\title{
Modelling of drying and cracking initiation in a gallery excavated in shale
}

\author{
H. Peron, J. Eichenberger, L. Laloui \& S. Salager \\ Ecole Polytechnique Fédérale de Lausann (EPFL)e, Laboratory of Soil Mechanics, Lausanne, Switzerland \\ P. Marschall \\ Nagra, Hardstrasse 73, CH-5430 Wettingen, Switzerland
}

\begin{abstract}
Damage induced by desiccation (i.e. drying shrinkage and cracking) is an issue to be investigated in deep geological nuclear waste storage engineering. A dried and cracked zone can form in the underground gallery host shale due to ventilation effects. Increase of the permeability and modifications of the mechanical properties of the shale could ensue. This study first presents a modeling framework able to address the issue of desiccation in shale. The advanced constitutive model ACMEG-S, which relies on multimechanism hardening plasticity is used. Conditions for mode I (opening) cracks initiation such as desiccation cracks are supposed to be met when the minor principal effective stress becomes equal to a threshold value (like in Griffith criterion). A finite element analysis of the coupled hydro-mechanical transient processes is further performed. A typical excavation from Mont Terri Underground Laboratory (Switzerland) is simulated, that could be caused by ventilation of the excavation. The results of the simulation clearly show the penetration of a drying front. The resulting effective stress distribution generates a gradual plastification at the neighborhood of the excavated gallery. It is shown how stresses develop during desiccation until a cracking criterion is reached.
\end{abstract}

\section{INTRODUCTION}

Damage induced by desiccation (i.e. drying shrinkage and cracking) is an issue in deep geological nuclear waste storage engineering. It affects clay barriers which are submitted to thermal and hydraulic coupled loads induced by the confined waste (Graham et al. 1997). A dried and cracked zone can also form in the underground gallery host shale due to ventilation effects (Ramambasoa et al. 2000).

More generally, desiccation cracking is also likely to alter the bearing capacity and/or overall stability of any type of earthen structures (Morris et al. 1992), as well as the permeability of clayey soil barriers for waste isolation (Albrecht \& Benson 2001). Furthermore, in soil science, desiccation cracks are of interest as it affects transport of gases, moisture and nutrients to the plant roots. Cracking affects the bulk properties of soils, especially their strength, compressibility, and permeability.

Evaporation of the wetting liquid (generally water) from the deformable porous medium (here the shale) induces drying shrinkage. The occurrence of desiccation cracks is made possible when the shrinkage is constrained, for specific conditions of suction and degree of saturation (Peron et al. 2009a). This paper presents a modelling framework able to address the processes of drying and desiccation crack- ing in shale. It is shown how stresses can be induced during drying, and a desiccation cracking stress criterion is proposed. These processes are further studied via the finite element modelling of the ventilation of an excavated gallery in shale.

\section{CONSTITUTIVE APPROACH FOR THE MODELLING OF DESICCATION}

The fundamental mechanical feature of geomaterials considered as deformable porous media relies on the notion of effective stress. Effective stress is a combination of both externally applied stresses and the internal pressure of fluid phases, and it enables the treatment of a multiphase porous medium as a mechanically equivalent single-phase continuum. For partially saturated media, it is expressed as (Nuth and Laloui 2008a):

$\sigma_{i j}^{\prime}=\left(\sigma_{i j}-p_{a} \delta_{i j}\right)+S_{r} s \delta_{i j}$

where $\sigma_{i j}^{\prime}$ is the effective stress tensor component, $\sigma_{i j}$ is the total stress tensor component, $p_{a}$ is the air pressure, and $\delta_{i j}$ is the Kronecker symbol. $S_{r}$ is the degree of saturation, $s$ is the suction. The direct dependence of the stress variable on suction and saturation degree bears the following coupling: drying, 
which corresponds to suction increase, will cause an increase in effective stress, and therefore shrinkage of the solid matrix. The other way round, wetting is at the origin of swelling. This is one of the features of the advanced constitutive model ACMEG-S (Nuth and Laloui 2008b).

ACMEG-S constitutive model is made of two main parts. The mechanical part accommodates nonlinear elasticity coupled with bounding multidissipative plasticity (one isotropic and one deviatoric mechanism), based on critical state concept. The water retention part defines the soil water retention curve, i.e. the relationship between the degree of saturation and the suction. Its mathematical formulation is based on kinematic hardening and features direct coupling with the mechanical stress-strain part of the model.

Conditions for mode I (aperture mode) cracks initiation such as desiccation cracks are supposed to be met when the minor principal effective stress becomes equal to a threshold stress value (like in Griffith criterion).

Based on experimental evidence, a criterion for the evolution with respect to suction of this threshold (denoted $\sigma_{t}^{\prime}$ ) is proposed by Peron (2008):

$$
\sigma_{t}^{\prime}=\sigma_{t}^{\prime s a t}+k_{2}\left[1-\exp \left(-k_{1} s / k_{2}\right)\right]
$$

$\sigma_{t}^{\text {sat }}$. is the value of the threshold at the saturated state (i.e. zero suction). $k_{2}$ and $k_{1}$ are material parameters accounting for the increase in $\sigma_{t}^{\prime}$ as suction increases. $k_{2}$ has the dimension of stress, and $k_{1}$ has no dimension.

In order to apply the above concepts, a coupled hydro-mechanical analysis of the non-homogeneous transient processes is performed in the following using the finite element method.

\section{FINITE ELEMENT MODELLING OF THE VENTILATION OF AN EXCAVATED GALLERY}

\subsection{Finite Element Model}

The finite element code Lagamine is used (Colin et al. 2002) in which ACMEG-S constitutive model is implemented (Nuth 2009). Lagamine performs a coupled thermo-hydro-mechanical analysis of the non-homogeneous transient processes. In isothermal conditions (present case), three primary state variables are used: gas pressure, water pressure, and displacement vector. The solid phase component is assumed to be incompressible (incompressible grains) while the water phase is (slightly) compressible. A Lagrangian formulation is adopted in the code.

\subsection{Assumptions of the Simulation}

A typical excavation from Mont Terri Rock Laboratory, Switzerland, is simulated, to reproduce isothermal drying of initially saturated Opalinus clay (the shale formation encountered there) that could be caused by ventilation of the excavation.

Bi-dimensional large strain finite elements are used. Each element has four degrees of freedom: two displacements for the soil skeleton, a liquid water pressure, a gas (dry air + vapour) pressure. Eight nodes isoparametric elements are used. For all the calculation results presented below, gas pressure is set constant and equal to atmospheric pressure. Therefore, only liquid transport is considered (darcean flux).

A gallery with a diameter equal to $2 \mathrm{~m}$. is studied. A plane perpendicular to the gallery axis is simulated, in plane strain conditions. A ca. $14 \mathrm{~m}$. deep zone from the gallery wall is considered ( 7 times the gallery radius). The dimensions of the domain have been chosen according to existing benchmarking exercise; see for instance Chavant and Fernandez (2005). The finite element mesh, the geometry and the mechanical boundary conditions that prevail in all the analysis are represented in Figure 1. Taking advantage of the symmetry, only a quarter of the domain is actually considered.

In-situ anisotropic stress state and pore water pressure are applied. The ventilation of the excavated gallery basically consists of imposing suction (i.e. a specified pore water pressure value) at the gallery wall, during a period of one year. The final value of suction $(100 \mathrm{MPa})$ corresponds to a relative humidity of $47.8 \%$ in the gallery.

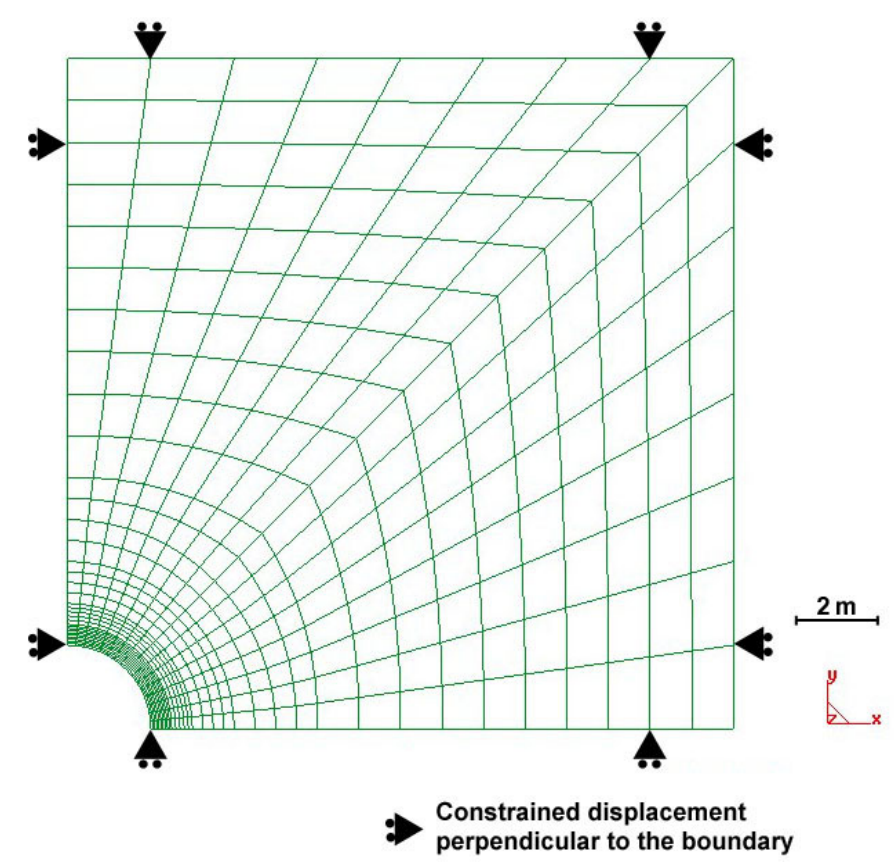

Figure 1. Finite element mesh used for the simulation of the drying of the gallery. 


\subsection{Model Parameters}

The ACMEG-S constitutive parameters of Opalinus clay were determined from mechanical and water retention tests results. In particular, the water retention curve of Opalinus clay has been determined upon drying, consisting of the measurement of void ratio, degree of saturation and water content at given levels of suction (Peron et al. 2007, Peron et al. 2009b). Two different suction imposition techniques have been used: axis translation technique and vapour equilibrium technique (for a suction range comprised between 0.02 and $327 \mathrm{MPa}$ ). The main drying curve has been determined, starting from a saturated sample $\left(s=0 \mathrm{kPa}, S_{r}=100 \%\right)$. The intrinsic permeability of the medium is equal to $2 \times 10^{-20} \mathrm{~m}^{2}$.

The values of $k_{1}$ and $k_{2}$ are respectively 0.5 and 8 $\mathrm{MPa}$ (experimental data allowing for determining these parameters are currently not available). The parameter $\sigma_{t}^{\text {sat }}$ is set to zero; this can be justified by the small tensile strength of Opalinus clay (Marschall et al. 2005).

\section{RESULTS AND DISCUSSION}

\subsection{Penetration of Drying}

After one year of drying, the penetration of a drying front appears clearly. The degree of saturation starts experiencing values significantly lower than $100 \%$ at about two meters from the wall, down to $40 \%$ at the tunnel wall (which corresponds to the imposed suction value, i.e. $100 \mathrm{MPa}$ ).

\subsection{Strain and Stress Fields}

Starting from a saturated state, the product "suction times degree of saturation" increases due to drying, this in turn induces an effective stress increase. The resulting effective stress distribution, shown in Figure 2 , is accompanied by a gradual plastification at the neighborhood of the excavated gallery. Plastic strains are caused by the progressive mobilization of the isotropic plastic mechanism of ACMEG-S, which intervenes before initial preconsolidation pressure being reached. Most of this process is made possible by the in-situ confining.

At this stage, a remark should be done: the simulations highlight that there is an overconsolidation process due to drying. This is primarily due to strain hardening that occurs as long as the material stays saturated $\left(S_{r}=100 \%\right)$, i.e. the suction remains below air entry value (Nuth and Laloui 2008a, Peron et al. 2009a).

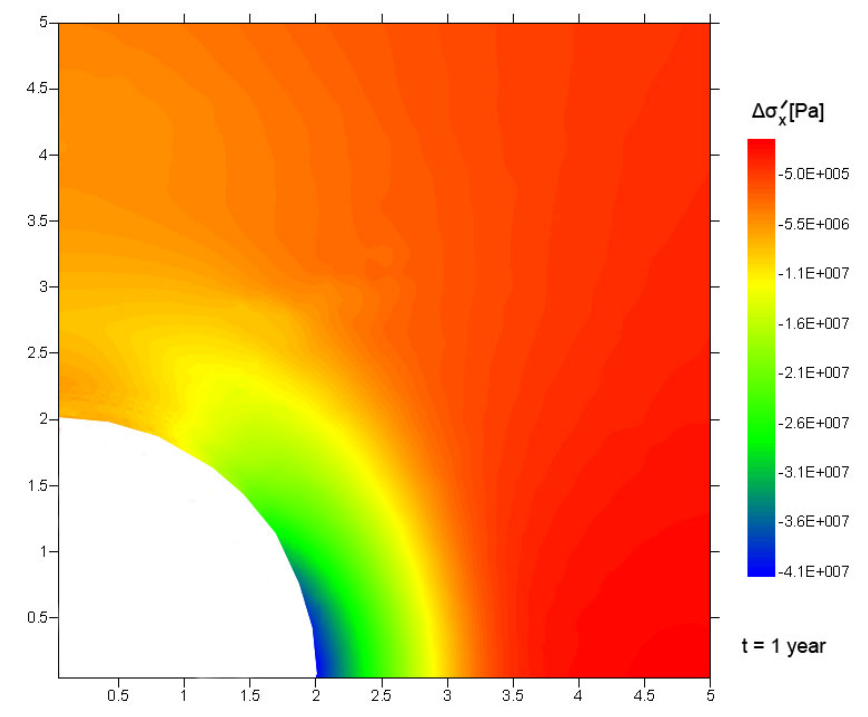

Figure 2- Horizontal effective stress around the tunnel after one year of drying. Compressive stresses negative.

\subsection{Occurrence of Desiccation Cracking}

The obtained effective stress repartition around the excavation may well be close to desiccation cracking criterion, due to three different phenomena.

Firstly (and independently from the drying process), the structural effect of the excavation within the host rock induces a release of stresses. The minor effective stress path is therefore shifted towards smaller stresses, closer to the cracking criterion. Secondly, the drying shrinkage of the zone near the excavation wall tends to be restrained by the still humid material located farther from the wall. This also tends to shift the minor effective stress path towards smaller stresses, which promotes desiccation cracking. Finally, the evolution of the cracking criterion with respect to suction, given by Equation 2 is such that, for the same effective stress level, cracking become more likely as suction increases.

In Figure 3, the evolution of the minor effective stress at the wall of the tunnel (crown) and a possible evolution trend for $\sigma_{t}^{\prime}$ with respect to suction are plotted. It is emphasized that values are plotted in terms of effective stress.

At the tunnel crown, the minor stress is horizontal; the desiccation cracks should therefore be orientated vertically. Note that the anisotropy of Opalinus clay is not taken into account here. Most probably, this can affect desiccation cracking orientation.

These results highlight the possibility of desiccation cracking as a result of coupled hydromechanical processes around underground excavated zones in shale. 


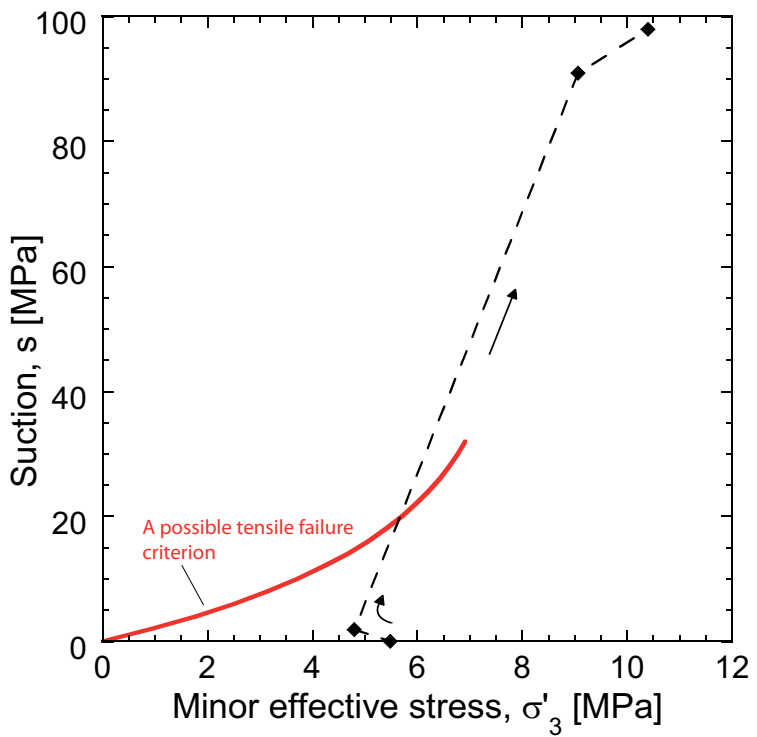

Figure 3- Evolution of the minor effective stress at the wall of the tunnel (crown) during the simulated period, and possible tensile failure criterion with respect to suction.

\section{CONCLUSIONS}

The finite element modelling was performed with Lagamine code, in which ACMEG-S is implemented. This allowed highlighting how effective stress can evolve around a representative tunnel located in Mont Terri Rock Laboratory when it is dried from its wall, as a result of changes in suction and degree of saturation. The elasto-plastic processes and the possible occurrence of mode I drying fractures were also simulated and commented.

\section{ACKNOWLEDGEMENT}

A part of this work was funded by the Swiss National Science Foundation (grant \# 200021 124702, "Assessment of soil damage induced by drying").

\section{REFERENCES}

Albrecht, B.A. \& Benson, C.H. 2001. Effect of desiccation on compacted natural clay. Journal of Geotechnical and Geoenvironmental Engineering 127: 67-75.

Collin, F., Li, X. L., Radu, J. P. \& Charlier, R. 2002. Thermohydro-mechanical coupling in clay barriers. Engineering Geology 64: 179-193.

Chavant, C. \& Fernandes, R. 2005. Evaluating the reliability of hydro-mechanical simulation: a benchmark of numerical techniques carried out by research group of MoMaS. In $2^{\text {nd }}$ International Meeting Clays in Natural and Engineered Barriers for Radioactive Waste Confinement, pp.249-250.

Graham, J., Chandler, N. A., Dixon, D. A., Roach, P. J., To, T. \&Wan, A. W. L. 1997. The Buffer/Container Experiment: Results, Synthesis, Issues. Atomic Energy of Canada Limited Report, AECL-11746, COG-97-46-I: Chalk River, $\mathrm{ON}$.

Morris, P.H., Graham, J., \& Williams, D.J. 1992. Cracking in drying soils. Canadian Geotechnical Journal 29: 262-277.
Marschall, P., Horseman, S. \& Gimmi, T. 2005. Characterisation of gas transport properties of the Opalinus clay, a potential host rock formation for radioactive waste disposal. Oil and Gas Science and Technology, rev. IFP 60(1): 121139.

Nuth, M. 2009. Advanced Modeling of Unsaturated Soils: Constitutive and Hydromechanically Coupled Finite Element Analysis. Doctoral Thesis, EPFL, Switzerland.

Nuth, M. \& Laloui, L. 2008a. Effective stress concept in unsaturated soils: clarification and validation of a unified framework. International Journal for Numerical and Analytical Methods in Geomechanics 32: 771-801.

Nuth, M. \& Laloui, L. 2008b. Advances in modelling hysteretic water retention curve in deformable soils. Computers and Geotechnics 35(6): 835-844.

Peron, H., Hueckel, T. \& Laloui, L. 2007. An improved volume measurement for determining soil water retention curve. Geotechnical Testing Journal 30(1): 1-8.

Peron, H. 2008. Desiccation Cracking of Soils. Doctoral Thesis, EPFL, Switzerland.

Peron, H., Hueckel, T., Laloui, L. \& Hu, L.B. 2009a. Fundamentals of desiccation cracking of fine-grained soils: experimental characterisation and mechanisms identification. Canadian Geotechnical Journal 46(10): 1177-1201.

Peron, H., Salager, S., Eichenberger, J., Rizzi, M. \& Laloui, L. 2009b. Experimental and numerical analysis of excavation damaged zone (EDZ) along tunnels. Mont Terri Project, Technical note 2008-54.

Ramambasoa, N., Nguyen-Minh, D. \& Rejeb, A. 2000. Hydromechanical behavior of a shale - Application to the Tournemire site. In $4^{\text {th }}$ NARMS, Pacific Rocks: Rock around the Rim, pp. 1067-1072. 